\title{
Development of a test for recording both visual and auditory reaction times, potentially useful for future studies in patients on opioids therapy
}

This article was published in the following Dove Press journal:

Drug Design, Development and Therapy

12 February 2015

Number of times this article has been viewed

\author{
Luca Miceli' \\ Rym Bednarova ${ }^{2}$ \\ Alessandro Rizzardo' \\ Valentina Samogin' \\ Giorgio Della Rocca' \\ 'Department of Anesthesia and \\ Intensive Care Medicine, University \\ of Udine, ${ }^{2}$ Department of Pain \\ Medicine and Palliative Care, Hospital \\ of Latisana, Latisana, Udine, Italy
}

Objective: Italian Road Law limits driving while undergoing treatment with certain kinds of medication. Here, we report the results of a test, run as a smartphone application (app), assessing auditory and visual reflexes in a sample of 300 drivers. The scope of the test is to provide both the police force and medication-taking drivers with a tool that can evaluate the individual's capacity to drive safely.

Methods: The test is run as an app for Apple iOS and Android mobile operating systems and facilitates four different reaction times to be assessed: simple visual and auditory reaction times and complex visual and auditory reaction times. Reference deciles were created for the test results obtained from a sample of 300 Italian subjects. Results lying within the first three deciles were considered as incompatible with safe driving capabilities.

Results: Performance is both age-related $(r>0.5)$ and sex-related (female reaction times were significantly slower than those recorded for male subjects, $P<0.05$ ). Only $21 \%$ of the subjects were able to perform all four tests correctly.

Conclusion: We developed and fine-tuned a test called Safedrive that measures visual and auditory reaction times through a smartphone mobile device; the scope of the test is two-fold: to provide a clinical tool for the assessment of the driving capacity of individuals taking pain relief medication; to promote the sense of social responsibility in drivers who are on medication and provide these individuals with a means of testing their own capacity to drive safely.

Keywords: visual reaction time, auditory reaction time, opioids, Safedrive

\section{Introduction}

Possessing a driving license plays a fundamental role in everyday life as it provides individuals with the liberty to have a mobile lifestyle. The right to such a lifestyle is also decided taking into account people affected by pathologies that require pharmacological treatment. Italian Road Law (article 187) stipulates restrictions regarding driving whilst under the influence of certain kinds of drugs, and these drugs are listed in a specific table published, and continuously updated, by the Ministry of Health. In addition to all illegal substances, this list includes the majority of benzodiazepines and opioid analgesics. The driving license is withdrawn from a driver when one or more of the listed substances are found in the individual's biological fluids and a physician or the police force concomitantly determine his/her psychophysical status as being altered - currently determined via the compilation of a report, the format of which is qualitative only and non-standardized.

Pharmacological therapies may alter the psychophysical status of drivers, with possible negative effects upon driving; ${ }^{1}$ thus, driving under the influence of such therapies could represent a potential cause of road accidents, with grave consequences
Correspondence: Luca Miceli Department of Anesthesia, University of Udine, Piazza Santa Maria Misericordia, 33100 Udine, Italy

Tel +393474507997

Fax +390432559502

Email miceli.luca@aoud.sanita.fvg.it 
in human, financial, and socio-economic terms. The following question therefore arises: should patients who drive whilst adhering to their pharmacological prescriptions be categorized as dangerous drivers due to their use of a determined drug type, or are we dealing with uninformed prejudice?

The authors are interested in this issue due to the widespread use of many of the drugs listed by the Ministry of Health as being prohibited when driving (particularly opioids); moreover, in addition to the potential increased probability of the patient suffering a road accident whilst on certain types of pain therapy, pain itself, if left untreated, could result in the deterioration of driving performance. ${ }^{2}$ To address this problem and in order to offer an objective tool to both medication-taking drivers and the police force for the evaluation of safe driving reflexes, namely, auditory and visual reflexes, we have developed a test that is executed using a dedicated smartphone app. The final purpose is to increase road safety for the patients taking psychotropic drugs by using a tool simply and "road side." We have chosen the visual and auditory reflexes because they are already used in our country (Italy) for the renewal of some types of driving licenses.

\section{Materials and methods}

In collaboration with software house Mobile 3D S.r.l. (Udine, Italy), we have developed an app for iPhones using an iOS Apple language ${ }^{3}$ that allows the user to perform the following four different tests of visual and auditory reaction times:

1. Simple visual test: The subject has to press a specific point on the smartphone's screen and then remove his/ her finger when the circle in the center of the screen lights up in green. The software measures the time taken to complete this operation and evaluates eventual errors in its execution (for instance, if the screen was not well pressed in the beginning or if the finger was removed too early or too late by more than 2 seconds). If the subject commits one or two errors, he/she must redo the test until ten repetitions have been successfully executed; if three errors are committed, the test will be interrupted and considered failed. The time between the screen being touched and the green light showing will randomly vary between 0.5 seconds and 2 seconds.

2. Simple auditory test: The subject has to press a precise point on the screen and remove his/her finger when the auditory tone, resembling a car horn, is heard. The software measures the time taken to complete this operation and evaluates eventual errors in its execution.
3. Complex auditory test: The subject has to press a bar on the screen and move his/her finger left or right toward the image of a dog or a cat according to whether dog or cat sound (bark or meow) is heard. The software measures the time taken to complete this operation and evaluates eventual errors in its execution.

4. Complex visual test: The subject has to press a bar on the screen and move his/her finger left or right toward the color green or red, in accordance with the color that appears in a circle in the center of the screen. The software measures the time taken to complete this operation and evaluates eventual errors in its execution.

When all four tests have been completed, the software presents a summary of the test results, indicating the total number of errors made as well as the mean time in milliseconds necessary to complete each test and the variance (a measure of the repeatability of the subject's performance). The results obtained can also be exported using the device's e-mail software; this option will enable the police to centralize the data collected in real time, so that the data can be used in parallel with the analysis of any biological samples obtained.

After approval by the Regional Ethical Committee of Udine and considering the actual demographic distribution of the Italian adult population (as reported by the National Institute of Statistics), subdivided by sex and age and normalized for adults over the age of 18 years (the legal minimum age for sitting a driving test in Italy), a sample of 300 individuals was selected to undergo the test, and their ages and sex corresponded with the above-mentioned distribution.

Inclusion criteria: Adult subjects (age $>18$ years) falling into the age and sex subgroups in accordance with the demographic distribution of Italian adults as reported by the Italian 2001 census; subjects able to drive, after written informed consent collection.

Exclusion criteria: Linguistic barriers; cognitive alterations incompatible with performing the tests; skeletal, muscular, or neurological disorders incompatible with performing the tests; the use of drugs acting upon the central or peripheral nervous system; eye diseases (excluding corrected refractive errors); and ear diseases (deafness or partial hearing loss).

\section{Statistical analysis}

All test results obtained using the app were e-mailed to a mail box created ad hoc. The data were imported and analyzed using Excel 2007 software (Microsoft, Seattle, WA, US).

The mean and variance values for all completed tests were used to create the corresponding deciles. A test was 
considered as having been "passed" if: the total number of errors committed in each subtest was two or less. The subjects passed all four subtests successfully, and the corresponding mean reaction time (expressed in milliseconds) and variance (expressed in milliseconds) lay between the fourth and tenth deciles.

The requirement for a driver's performance values to fall above the third decile for both reaction time and variance was selected in accordance with item 119 of Italian Road Law, where a complete description of necessary requisites for obtaining and maintaining various types of driving licenses, including nautical driving licenses, is described.

\section{Results}

Once the reference deciles for the Italian population were obtained (Table 1) and the number of subjects who had passed the entire test were calculated, the subjects were then categorized according to the age and the sex (Table 2) and the results obtained by the app were analyzed according to these age and sex categories by decade (the subjects aged between 20 years and 90 years were considered; the division of age by decade was used as previously described by $\mathrm{Cox}^{4}$ ). Pearson's regression coefficient, $r$, was calculated using Microsoft Excel software (Table 3) to evaluate how performance varies in relation to the age. Student's twotailed $t$-tests for unpaired samples were calculated to analyze potential correlations with sex (Table 4).
A female to male predominance (51.7\% versus $48.3 \%)$ was observed, with females exhibiting a higher mean age compared to males (53.4 years versus 49.9 years, $P>0.05$, not significant, NS; Student's $t$-test for unpaired samples).

Table 1 presents the reference deciles for the sample population (stratified by age decade, starting with the age of 20 and ending with the age of 90) for each of the four subtests conducted (the mean reaction time in ms and the variance were analyzed separately); this table was used to fine-tune the app itself by inserting the deciles values.

Table 2 and Figure 1 describe and quantify the subjects that successfully passed all four subtests in relation to both components, ie, reaction time and variance (to pass the test, the mean reaction time and variance must lie between the fourth and tenth deciles). It is important to highlight here that only $21 \%$ of the subjects successfully completed the entire test $(25.51 \%$ of males versus $16.77 \%$ of females); when further stratified by the age decade, the highest percentage of subjects successfully completing the entire test were aged between 20-29 years and 30-39 years, with success rates diminishing for the successive age groups. For the age groups over 60 years, all the subjects successfully completing the test were male.

Table 3 analyzes the correlation between age and performance (expressed as Pearson's linear regression coefficient, $r$ ); statistical significance $(r>0.5)$ was noted for all tests independent of whether the analysis considered all subjects together or each sex separately.

Table I Reference deciles for mean reaction times (ms) and variance (ms)

\begin{tabular}{|c|c|c|c|c|}
\hline & Test I mean & Test I variance & Test 2 mean & Test 2 variance \\
\hline I0th decile & $<279.93$ & $<0.1415$ & $<315$ & $<0.1493$ \\
\hline 9th decile & $294.3-279.93$ & $0.1858-0.1415$ & $334.33-315$ & $0.166-0.1493$ \\
\hline 8th decile & $308-294.3$ & $0.2192-0.1858$ & $346.38-334.33$ & $0.1867-0.166$ \\
\hline 7th decile & $324.35-308$ & $0.2413-0.2192$ & $366.6 I-346.38$ & $0.206 I-0.1867$ \\
\hline 6th decile & $351.99-324.35$ & $0.2672-0.24 I 3$ & $380.55-366.61$ & $0.2202-0.206 \mathrm{I}$ \\
\hline 5th decile & $380.06-351.99$ & $0.2902-0.2672$ & $402.18-380.55$ & $0.24 I 7-0.2202$ \\
\hline 4th decile & $439.82-380.06$ & $0.3169-0.2902$ & $444.28-402.18$ & $0.2665-0.2417$ \\
\hline 3rd decile & $529.92-439.82$ & $0.3859-0.3169$ & $561.05-444.28$ & $0.2854-0.2665$ \\
\hline 2nd decile & $671.31-529.92$ & $0.4618-0.3859$ & $815.18-561.05$ & $0.3407-0.2854$ \\
\hline \multirow[t]{2}{*}{ Ist decile } & $>671.31$ & $>0.4618$ & $>815.18$ & $>0.3407$ \\
\hline & Test 3 mean & Test 3 variance & Test 4 mean & Test 4 variance \\
\hline I0th decile & $<438$ & $<0.1064$ & $<535.37$ & $<0.1291$ \\
\hline 9th decile & $473.66-438$ & $0.1222-0.1064$ & $560.99-535.37$ & $0.1470-0.1291$ \\
\hline 8th decile & $503.02-473.66$ & $0.1370-0.1222$ & $574.5-560.99$ & $0.1633-0.1470$ \\
\hline 7th decile & $526.28-503.02$ & $0.1499-0.1370$ & $605.57-574.5$ & $0.1789-0.1633$ \\
\hline 6th decile & $547.45-526.28$ & $0.164 I-0.1499$ & $639.5-605.57$ & $0.1919-0.1789$ \\
\hline 5th decile & $587.82-547.45$ & $0.1755-0.164 \mid$ & $673.75-639.5$ & $0.2041-0.1919$ \\
\hline 4th decile & $635.69-587.82$ & $0.1927-0.1755$ & $728.89-673.75$ & $0.2208-0.204 \mid$ \\
\hline 3rd decile & $707.32-635.69$ & $0.2216-0.1927$ & $821-728.89$ & $0.2379-0.2208$ \\
\hline 2nd decile & $936.97-707.32$ & $0.2606-0.2216$ & $|067.48-82|$ & $0.2667-0.2379$ \\
\hline Ist decile & $>936.97$ & $>0.2606$ & $>1067.48$ & $>0.2667$ \\
\hline
\end{tabular}


Table 2 Subjects successfully passing all four tests

\begin{tabular}{lllll}
\hline $\begin{array}{l}\text { Age } \\
\text { (years) }\end{array}$ & $\begin{array}{l}\text { Males } \\
(\mathbf{n})\end{array}$ & $\begin{array}{l}\text { Females } \\
(\mathbf{n})\end{array}$ & $\begin{array}{l}\text { Males } \\
\text { enrolled (n) }\end{array}$ & $\begin{array}{l}\text { Females } \\
\text { enrolled (n) }\end{array}$ \\
\hline $20-29$ & $8(44.44 \%)$ & $6(37.5 \%)$ & 18 & 16 \\
$30-39$ & $9(34.61 \%)$ & $8(33.33 \%)$ & 26 & 24 \\
$40-49$ & $9(30 \%)$ & $8(27.59 \%)$ & 30 & 29 \\
$50-59$ & $5(20.83 \%)$ & $4(16.66 \%)$ & 24 & 24 \\
$60-69$ & $5(21.74 \%)$ & 0 & 23 & 26 \\
$70-79$ & $1(6.25 \%)$ & 0 & 16 & 21 \\
$80-89$ & 0 & 0 & 8 & 12 \\
$>90$ & 0 & 0 & 1 & 2 \\
Total & $37(25.51 \%)$ & $26(16.77 \%)$ & 146 & 154 \\
\hline
\end{tabular}

No significant differences were found when we analyzed for correlations between age and variance, irrespective of whether subjects were analyzed altogether or subdivided by sex (results not indicated in the table).

Finally, we analyzed for differences between the two sexes (Table 4) with regard to performance in each of the four subtests: Student's two-tailed $t$-tests for unpaired samples revealed a statistical significance $(P<0.05)$ in favor of the males for each of the four subtests analyzed; when we stratified the analysis according to the age decade, statistical significances were revealed between sexes for the age groups of 30-39 and 50-59.

\section{Discussion}

The decision to assess visual and auditory reflexes as a way of evaluating the psychophysical state of drivers was not casual: in the literature, driving performance has been evaluated in different ways: through the use of driving simulators, ${ }^{5}$ "on the road" tests conducted on roads closed to traffic, ${ }^{6}$ using the Vienna test (used in some European countries to evaluate driving suitability for driving license renewals or when a driving license is to be obtained for the first time ${ }^{7}$ ), or through the assessment of visual and/or auditory reflexes. ${ }^{8}$ We chose to evaluate visual and auditory reflexes as a proxy of driving "fitness," not only because they are easy to assess using software for mobile devices, but principally because threshold values regarding these reflexes are already indicated in Italian Road Law.

The time employed to move the finger away from the screen was assessed rather than the other way round in order

Table 3 Pearson's regression coefficient, $r$, between age (all subjects, men only, and women only) and test performance

\begin{tabular}{lllll}
\hline Pearson's $\mathbf{r}$ & Test I & Test 3 & Test 2 & Test 4 \\
\hline Age total & $0.6 *$ & $0.698^{*}$ & $0.566^{*}$ & $0.648^{*}$ \\
Age males & $0.599^{*}$ & $0.638^{*}$ & $0.570^{*}$ & $0.575^{*}$ \\
Age females & $0.609^{*}$ & $0.736^{*}$ & $0.556^{*}$ & $0.697^{*}$ \\
\hline
\end{tabular}

Note: *if Pearson's $r>0.5$.
Table 4 Student's two-tailed t-tests for unpaired samples to assess for performance differences between the two sexes

\begin{tabular}{lllll}
\hline Student's t-test & Test I & Test 2 & Test 3 & Test 4 \\
\hline 20-29 years & 979 & 0.94 & 747 & 362 \\
30-39 years & $0.02 I^{*}$ & $0.018^{*}$ & $0.004^{*}$ & $0.044^{*}$ \\
$40-49$ years & 147 & 283 & 758 & 516 \\
$50-59$ years & $0.04 I^{*}$ & $0.026^{*}$ & 88 & $0.030^{*}$ \\
$60-69$ years & 914 & 327 & 713 & 823 \\
$70-79$ years & $0.049 *$ & 0.13 & 85 & 804 \\
$80-89$ years & 161 & 92 & 67 & 955 \\
$>90$ years & NA & NA & NA & NA \\
Total & $0.001 I^{*}$ & $0.0145^{*}$ & $0.0077^{*}$ & $0.0128^{*}$ \\
\hline
\end{tabular}

Note: $* P<0.05$, Student's $t$-test.

Abbreviation: NA, not available.

to eliminate the bias that would be created by initial finger distance from the screen, as it would be very difficult to standardize this distance. We also developed a software graphical interface so that left-handed individuals could perform the test in the same way as right-handed individuals.

As simple reflexes, we used the switching on of a light (test 1, simple visual) and an auditory tone (test 2, simple auditory), while as complex reflexes we introduced color discrimination (test 3, complex visual) and sound type discrimination tests (test 4 , complex auditory) that require advanced processing by the brain. The speed of test execution was measured in milliseconds and its repetitiveness by means of the variance.

The fact that only $21 \%$ of subjects passed the entire test allows us to make the following considerations: considering that visual and auditory reflex tests are only obligatory in Italy for special types of driving licenses and not for motorcycle licenses (Type A driving license) or for vehicles that weigh less than 3,500 $\mathrm{kg}$ (Type B driving license), we believe that Italian Road Law provisions regarding reflex reaction times are too rigorous and would prevent a large portion of capable drivers from obtaining special types of driving licenses.

The anticipated negative correlation between subject age and performance has been previously reported in the literature ${ }^{9,10}$ and correlates with a series of cerebral deteriorations involved in aging; the superior performance of male drivers over females has also been previously observed. ${ }^{11,12}$ However, the present results indicate that even though male performances are statistically superior to those of females, there are two age decades that predominantly contribute toward this overall result: subjects aged 30-39 years and 50-59 years. At present, we can offer no explanation for this phenomenon; a larger sample may better clarify this result. 


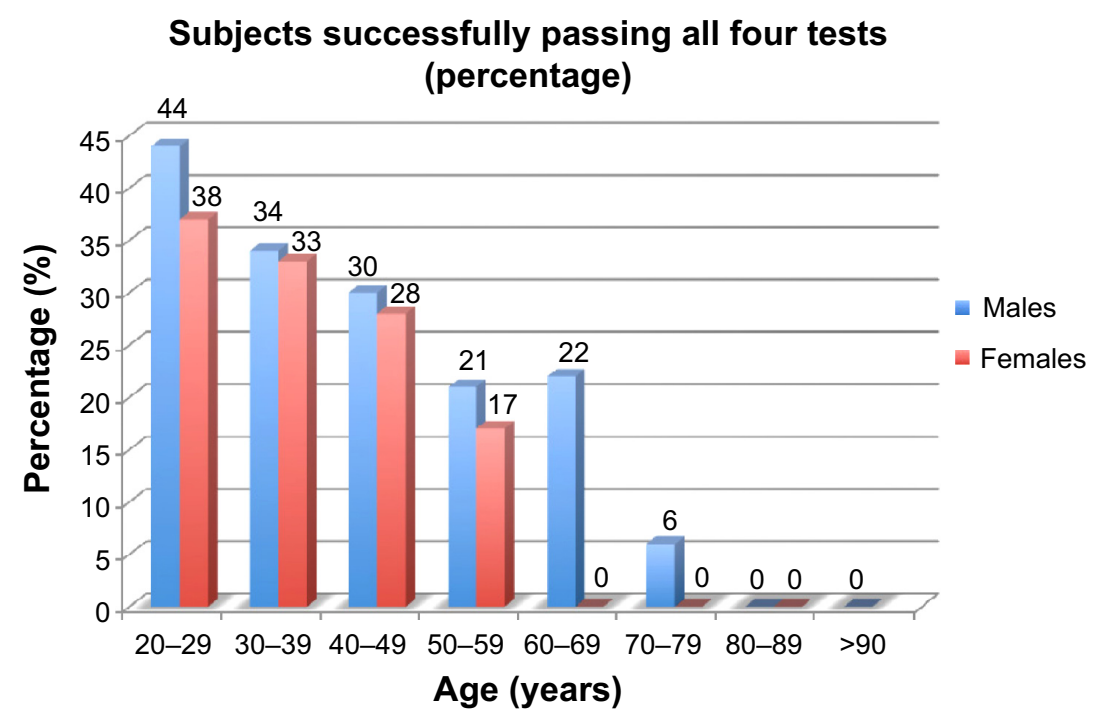

Figure I Quantification of subjects who successfully passed all four subtests.

The authors ${ }^{13}$ recently studied with the "Safedrive" app a group of patients before and after opioid therapy (oxycodonnaloxon association); the results showed that pain aggravates the visual and auditory reflexes status when patients with severe non-cancer pain (numerical rate scale [NRS] $>6$ on a scale with eleven points) are compared with healthy volunteers. After two weeks of opioid therapy (and pain control with NRS $<3$ ), the authors showed that the opioid therapy did not adversely affect the patients' performance, and were found to be better than those of healthy volunteers with a blood alcohol concentration less than $0.5 \mathrm{~g} / \mathrm{L}$, which is allowed by Italian Road Law.

This software could be useful in a number of ways; for example, a significant proportion of the general population is currently undergoing treatment with drugs (including, opioid analgesics, benzodiazepines, etc.,) that act on the central nervous system. Thus, the present app represents a simple-to-use and free mobile tool for the evaluation of psychophysical status (in a similar sense to home breathalyzers), the responsible use of which could reduce the probability of the subject being involved in a road accident and subsequent prosecution by the authorities for driving under the influence of psychotropic substances. The police force would also benefit from being equipped with this app, as they would have an objective and repeatable procedure for evaluating psychophysical status without the need for the services of a physician. The actual situation in Italy regarding the evaluation of these parameters is highly variable as no objective and repeatable method has been available.

As our end objective is to offer this tool to the police force, the software was developed and fine-tuned considering the specific driver skills required by Italian Road Law.
The overall goal of this research is to generate responsible driving culture, provide information, and promote the awareness of the problem of driving under medication so that patients taking psychotropic drugs (in the range of millions of patients per year in Italy alone) avoid driving when experiencing an altered psychophysical status. On the other hand, it is also fair that patients taking medication should be able to enjoy an autonomous lifestyle when they are fit to do so; indeed, psychotropic drugs (opioid analgesics in particular) do not necessarily create problems for driving, whereas other drugs like antihistamines and benzodiazepines are not always safe (data available on www.druid-project.eu); thus, patients who use opioid analgesics or other psychotropic drugs are often being unfairly discriminated against.

This app can contribute to supporting and helping both patients and traffic police (especially if the app's use becomes widespread on the national level) so that in addition to subjective evaluations, a realistic objective parameter that measures visual and auditory reflexes can help promote and ensure good driving performance despite the prejudices and concerns regarding the use of psychotropic and narcotic drugs listed by the Ministry of Health during driving.

\section{Conclusion}

We have designed, developed, and fine-tuned the software for a test to assess visual and auditory reaction times. The scope of the test is two-fold: to provide a clinical tool for the assessment of driving capacity of drivers who are on pain relief medication (helping to avoid the unfair prosecution of drivers, according to article 187 of Italian Road Law) and; to promote the sense of social responsibility in drivers on 
medication and provide these individuals with a means of testing their own capacity to drive safely, thereby reducing the number of road accidents caused by inadequate visual and auditory reaction times.

This software holds the potential to bridge the statisticalepidemiological gap during the evaluation of the role of the psychophysical status of a driver involved in a car accident. In 2011, no data regarding car crashes caused by alterations in driver psychophysical status were listed or analyzed in the National Institute of Statistics Annual Report directly due to the absence of an objective and repeatable method of psychophysical performance evaluation.

All these considerations should contribute toward reducing patient ignorance about the risks associated with driving whilst taking certain forms of medication as well as unnecessary apprehension and anxiety surrounding the use of some psychotropic drugs - in particular, analgesic opioids, which, when administrated correctly, may not necessarily present problems in patients that need to drive, especially if slow-release preparations are used (for example, oxycodonecontrolled release $\left.{ }^{14}\right)$.

On the other hand, weak opioids that are not listed in the ministerial table have sometimes been found in the blood of car accident victims. ${ }^{15}$

A simple, objective, "road side" tool with the function of measuring the driving abilities appears to be very important in order to ensure road safety of all citizens and avoid discrimination of patients with chronic pain.

\section{Disclosure}

The authors report no conflicts of interest in this work.

\section{References}

1. Rapoport MJ, Baniña MC. Impact of psychotropic medications on simulated driving: a critical review. CNS Drugs. 2007;21(6):503-519.

2. Veldhuijzen DS, van Wijck AJ, Wille F, et al. Effect of chronic nonmalignant pain on highway driving performance. Pain. 2006;122:28-35.

3. Deary IJ, Der G, Ford G. Reaction time and intelligence differences: a population-based cohort study. Intelligence. 2001;29:389-399.

4. Blaxter M. Sample and data collection. In: Cox BD, editor. The Health and Lifestyle Survey. London: Health Promotion Research Trust; 1987:1-3

5. Nilsen HK, Landro NI, Kaasa S, Jenssen GD, Fayers P, Borchgrevink PC. Driving functions in a video simulator in chronic non-malignant pain patients using and not using codeine. Eur J Pain. 2011;15(4):409-415.

6. Verster JC, Mets MA. Psychoactive medication and traffic safety. Int J Environ Res Public Health. 2009;6(3):1041-1054.

7. Jehkonen M, Saunamäki T, Alzamora AK, Laihosalo M, Kuikka P. Driving ability in stroke patients with residual visual inattention: a case study. Neurocase. 2012;18(2):160-166.

8. Kopp M, Knuenz A, Oberascher F, et al. Psychomotor car-driving abilities after robotically assisted totally endoscopic coronary artery bypass grafting. Thorac Cardiovasc Surg. 2012;60(7):462-467.

9. Der G, Deary IJ. Age and sex differences in reaction time in adulthood: results from the United Kingdom Health and Lifestyle Survey. Psychol Aging. 2006;21(1):62-73. [Erratum in: Psychol Aging. 2009; 24(1):229].

10. Ansey KJ. Sensorimotor variables and forced expiratory volume as correlates of speed, accuracy, and variability in reaction time performance in late adulthood. Aging Neuropsycol Cogn. 1999;6:84-89.

11. Reimers S, Maylor EA. Gender effects on reaction time variability and trial-to-trial performance: reply to Deary and Der (2005). Neuropsychol Dev Cogn B Aging Neuropsychol Cogn. 2006;13(3-4):479-489.

12. Silverman IW. Sex differences in simple visual reaction time: a historical meta-analysis. Sex Roles. 2006;54:57-68.

13. Miceli L, Bednarova R, Rizzardo A, Marcassa C, Della Rocca G. Alcohol, pain, and opioids: which is a major threat to driving ability? Ann Pharmacother. 2014;48(11):1531-1532.

14. Gaertner J, Radbruch L, Giesecke T, et al. Assessing cognition and psychomotor function under long-term treatment with controlled release oxycodone in non-cancer pain patients. Acta Anaesthesiol Scand. 2006;50:664-672.

15. Goeringer KE, Logan BK, Christian GD. Identification of tramadol and its metabolites in blood from drug-related deaths and drug-impaired drivers. J Anal Toxicol. 1997;21:529-537.
Drug Design, Development and Therapy

\section{Publish your work in this journal}

Drug Design, Development and Therapy is an international, peerreviewed open-access journal that spans the spectrum of drug design and development through to clinical applications. Clinical outcomes, patient safety, and programs for the development and effective, safe, and sustained use of medicines are a feature of the journal, which

\section{Dovepress}

has also been accepted for indexing on PubMed Central. The manuscript management system is completely online and includes a very quick and fair peer-review system, which is all easy to use. Visit http://www.dovepress.com/testimonials.php to read real quotes from published authors. 